about five sessions a week. This was mostly for social services and particularly giving advice on the management of children and adolescents, which is a very old interest of mine that re-surfaced when the opportunity arose. Then, after some years, we decided for domestic reasons, to retire to Devon, and for the last few years there, I have worked two sessions a week and done occasional medico-legal work. I feel I have been a singularly fortunate and happy man in my profession.

From your present position, what do you feel about the ways things are going now - how psychiatry has developed in recent years, and the way it seems to be going at present, with Griffiths and the other changes?

Personally, I'm optimistic and hopeful. In 1984, with Dr Reardon and Dr Rogers, we did a series of visits to psychiatric units in general hospitals. This was written up by the HAS and called The Changing Pattern of Care in Psychiatry. It demonstrated very clearly that there are a lot of young, energetic psychiatrists with both new ideas and the ability and the courage to implement them, and that many interesting new services are developing. I've no doubt that psychiatry has changed dramatically and is still changing; it is necessary for the young men and women in psychiatry to have the courage of their opinions and to produce new ideas and to implement them. I was lucky in my career, and could do this. I have no doubt that there are many other, more able people who could do the same and better. I'm well aware of the current frustrations with money shortages, the need to fit in with management policies, and managers who may not even understand psychiatric needs. But I still think there are ample opportunities for someone who is willing to look for them, to convince people and to talk their way into a situation where things can be done. This is certainly the case in developing a service to general practice, and community work generally.

\section{Do any trends worry you?}

I am uneasy about a number of trends; in particular, I think the legal threat which hangs over doctors nowadays makes them practise defensively. I am sure this is one reason why ECT is not used as frequently or as freely as it should be, and I think this deprives many patients - schizophrenics as well as depressives - of their best chance of a good-quality recovery. The present tendency to assume that every patient must have a detailed plan on leaving hospital doesn't make allowance for human nature. All these plans need to be flexible and particularly flexible in response to the patient's wishes, as opposed to what staff may feel is good for them. I still think psychiatry is a cinderella profession and runs the risk of being outvoted and out-mancuvred by other professionals. This, of course, holds true for geriatrics too. Yet I think psychiatrists complain too readily about their difficulties in relationships with other professions, particularly social workers. As I see it, a psychiatrist's job is not just to make good relationships with patients, but also with other professionals. If he can apply his skills to one, he should apply them to the other. I think that makes life much easier and much more interesting.

\title{
Compulsion in psychiatry: blessing or curse?
}

\author{
ANATOLIY KoRyagin, Am Brunnenbächli 8, CH-8125 Zollikerberg, Switzerland
}

It is common knowledge that psychiatric patients sometimes need to have compulsory measures applied to them for the safety of themselves and of others.

In the Soviet Union compulsory measures have always been used with mentally ill persons by way of compulsory psychiatric examination and compulsory treatment.

At present there is much talk of reforms in the socio-political and economical life of the USSR. Many people know already of the new "Regu- lations" on handling mentally ill persons, in force since 1 March 1988.

This is what it says in item 9 of the said Regulations:

"A person committing actions that give sufficient reason to assume the existence of a pronounced mental disorder in him, who violates the public order or the rules of socialist communal life and/or represents an immediate danger to himself or his associates, may be submitted to an initial examination without his consent or the consent of his relatives or legal representatives." 
It is noteworthy that the violation of the public order or of the "rules of socialist communal life" are taken into consideration in the first place and only secondly an immediate endangering of the person himself or his surroundings. In the instructions of 21 March 1988, it is said that such an examination may be conducted at the request of somebody's relatives, of state bodies and public organisations, acquaintances, and neighbours.

All legal intervention is excluded in such a case; all competence resides with the psychiatrist or even with a physician substituting for the former. This may be appealed against only afterwards, after the action has occurred.

Compulsory treatment is administered in psychiatric clinics with various maintenance conditions to mentally ill persons having committed crimes when not answerable for their actions, or having fallen ill while serving a sentence. The court decides about this kind of treatment.

A forensic psychiatric examination is ordered by the examining magistrate if he has "sufficient grounds to assume the existence of a mental disorder in the person under investigation" or by the administration of the prison or camp where a convict is.

In the Soviet Union, questions of danger to the public from a mentally ill person are dealt with not only by psychiatrists, but also by lawyers, whose definitions of the phenomenon vary. Physicians define it as a danger to the health and life of the ill person as well as to his surroundings; the lawyers, broadening the concept, include also a potential danger of a violation of laws and a danger to the community's foundations. Inasmuch as in Soviet social relationships there is pre-eminence of the state over the individual and, as the Soviet legal system is the foremost guardian of the regime existing in the country, it is perfectly clear why the special instructions of the Health Ministry of the USSR in defining the public danger of a mentally ill person recommend not only that his clinical-psychopathological, but also that his socio-psychological symptoms, should be considered.

Apart from hallucinatory-delusional states and disorders of one's frame of mind known for their dangerousness, in the first place they name such a manifestation of mental pathology as a "psychopatho-like syndrome with intensified behaviouristic activity and drive disorders" as well as hypomanic conditions "with loss of inhibitions and pseudoenterprise".

Of socio-psychological factors enhancing the risk of socially dangerous behaviour, the official instructions "on the application of compulsory means" list the following:

(a) signs of social maladjustment, manifesting itself by way of a person's not working and having no job, not being provided for financially, not being settled (in particular, lacking a regular place of residence), having no family or having family trouble, being susceptible to asocial influences

(b) a tendency to systematic consumption of alcohol, drugs, and other toxic substances

(c) the manifestation of criminal behaviour before the disorder, repeated committing of socially dangerous actions

(d) violation of the hospital regime during earlier hospitalisation in psychiatric hospitals.

From what has been said, it is not difficult to see the undisguised crudity with which the element of a person's social behaviour sticks out from the Soviet definition of social dangerousness. It is not without cause either. The sources of such an interpretation need to be looked for in the history of the Soviet socio-political system.

The fact that mentally ill persons need a special legislation does not call for proof, for firstly, many of these people are bearers of the potential danger of committing a crime; secondly, their mental disability turns them into the most defenceless group within society and therefore their helplessness calls for legal protection.

In a dictatorial State with a totalitarian regime, such as the USSR, the laws have at all times served not the aim of self-regulation of the life of society but have been one of the main levers by which to manipulate the subjects' behaviour. Every Soviet citizen has always been directly called state property and been considered not as the aim, but as a means to reach the aims of the rulers. From the point of view of state pragmatism, a mentally ill person is considered as a burden to society, not producing anything and using up the state's material means without recompense, and even potentially capable of doing harm. Therefore the Soviet State never deemed it reasonable to pass special legislative acts protecting the legal as well as the material part of the life of these patients.

It was only instructions of the medical and legal departments that stipulated certain rules of handling the mentally ill and application of various sanctions to them. A person suffering from a mental disorder was automatically deprived of all rights and depended wholly on the psychiatrists' will. Practically anybody could be subject to a psychiatrist's examination on the most foolish grounds and the diagnosis issued made him into a person without rights.

It was this lack of legal rights and guarantees that favoured the organisation of a system of repressive psychiatry in the country. The authorities and the KGB, vested with the possibility of exerting pressure on the psychiatrists, managed to have mentally sound dissidents tucked away in psychiatric clinics, where with the assistance of scoundrels among the 
psychiatrists they were exposed to torture with neuroleptics, physical violence, and crude moral pressure. Having begun during Khrushchev's rule, these repressions were most widely used in the Brezhnev era. During the '70s and first half of the ' 80 s, every person under investigation under an "anti-Soviet" paragraph of the penal code underwent a forensic-psychiatric examination, and every second or third among them was diagnosed as a mental case and sent to a mental institution, sometimes for many years on end or repeatedly.

Anyone daring to speak up against psychiatric repression was persecuted by the KGB with particular brutality. Between 1979 and 1981 all six members of the (unofficial) commission for investigation of political abuse of psychiatry were thrown into prison. The most scandalous facts of political abuse of psychiatry in the country were flatly denied by the Soviet authorities and the official leaders of psychiatry. In 1983 the official Soviet psychiatrists' society was compelled to leave the WPA in order to escape the shame of being excluded by this organisation.

The counteraction against penal actions by psychiatrists from within Soviet society, and the pressure brought on by criticism from abroad, have forced the Soviet authorities in the era of Gorbachov's perestroika to concern themselves with a transformation of psychiatry. To what extent they have made headway is shown by the extracts from the new "Regulations" quoted above. Even Soviet lawyers submit it to the most serious criticism, stating bluntly that these regulations in no way guarantee the patients' legal protection. Notwithstanding the fact that the "Regulations" do indeed stipulate the patient's right to appeal against psychiatrists' actions, the decision about hospitalisation is still made by the physician alone, who need not even necessarily be a psychiatrist.

The imperfection of the new "Regulations" with their scant legal guarantees has its reasons. The conservative forces of Soviet society participated in drawing it up - the official legal bodies and the psychiatric "establishment". The lawyers were guided by the well-established rule of Soviet legislators: "A law must be worded in such a way as to permit its arbitrary application". The present leaders of Soviet psychiatry, many of whom are responsible for political abuse of their profession, would of course never deliberately support the creation of a new, lawful climate in the country's psychiatry-against which backdrop their own former crimes would appear in striking contrast.

With the development of the glasnost process in the USSR, relations between the leadership of official Soviet psychiatry and the authorities have gained a hitherto unprecedented form. Gorbachov got a perfectly real possibility to dissociate himself from the policy of penal psychiatry by declaring it to be a heritage of the past, and he permitted public criticism of this form of repression. But while Khrushchev and Brezhnev cannot be called to account, the immediate organisers and perpetrators of these repressions, viz. psychiatrists (there are such among the leading ones also) are still alive and they can be presented the bill for the crimes committed. That is why official psychiatry continues to defend itself so violently against this criticism, home-made now: taking care not to overstep the framework of glasnost, Soviet psychiatrists have criticised the psychiatric system in the country for its inadequate organisation, the theoretical foundation of psychiatry, the unsatisfactory training of physicians and their lack of conscientiousness - dismissing all abuse as "individual mistakes". Indeed they resorted to all sorts of tricks in order to evade having to admit the existence of a system of political abuse of psychiatry, which can easily be demonstrated by the following arguments:

(1) dissidents were invariably examined by the most experienced psychiatrists, in the Serbsky Institute by professors

(2) the inconceivably high "sick rate" among dissidents (very few of them were not subject to a forensic-psychiatric examination, and in the ' 60 s and '70s, every third dissident was despatched to a psychiatric clinic)

(3) cases of establishing a "collective" diagnosis (in 1987, four Armenian members of the Hari Krishna grouping who were under one and the same case, had the diagnosis of schizophrenia established simultaneously; the Kutyavin couple were hospitalised together and released together)

(4) establishing a diagnosis without seeing a patient, even without having had any contact with him

(5) diagnoses of victims of psychiatry included in most cases a "delusion syndrome"

(6) the explicit offer by physicians and KGB officers to victims of penal psychiatry: release in exchange for giving up their former social behaviour

(7) using "repentant" patients of penal psychiatry for giving statements on the radio and television

(8) repetition of one and the same "mistake" regarding one and the same dissident by various psychiatrists over many years.

In spite of the obviousness of the system of abuse, in spite of continued abuses, in spite of hundreds of former victims of psychiatry fighting for rehabilitation, and although it continued to flatly repudiate all accusations, official Soviet psychiatry set out to get back into the WPA. This was directly promoted 
by the present change - altogether unstable - in the USSR's psychological climate and by support from the former WPA leadership.

Much depended on the congress in Athens. The leaders of Soviet psychiatry understood that if they were readmitted this would automatically rehabilitate them in the eyes of public opinion and they could then report to the authorities that their Western colleagues had sufficient respect for them. This in turn would secure for all of them their former position and also protection from criticism and juridical responsibility. If they were not accepted, they would forfeit, at the authorities' discretion, their position and become vulnerable to attacks from without.

In the case of replacement of the old leadership of Soviet psychiatry, very quick and deep changes would occur in this branch of medicine. As is known, an Independent Psychiatric Association (IPA) has already been founded in the USSR, setting the course for a substantial renewal of Soviet psychiatry. This organisation's statutes preclude the adherence of psychiatrists involved in abuse of psychiatry. It is this association that would act as a kind of 'filter' identifying honest psychiatrists. With a new leadership, official psychiatry too would be renewed.

However, at the Athens congress Western psychiatrists did a disservice to Soviet psychiatry. As is already known, alongside the IPA the official Soviet psychiatrists' society was also accepted as a regular WPA member. And this happened in spite of the fact that while the congress was going on new victims became known-six people were locked up in the psychiatric clinic at Talgar (Kazakhstan) for political motives.

As an honorary member of the WPA, I was present at the general assembly of 17 October 1989 . It was the Americans who set the fashion. First a resolution was voted: "If official Soviet psychiatry will be admitted, this will be only on certain conditions". The majority voted for. After this they voted "admit - not admit". It is quite natural that after the first voting, the second was a mere formality. The conditions that were set: "Within a year a commission will be sent to the USSR by the WPA to check on cases of abuse, and if such cases will be established, to call an extraordinary general assembly and raise the question of excluding the Soviet society from the WPA". Upon my application to the president asking him to allow me to take the floor, I received no answer.

The fact that alongside official psychiatry the IPA was admitted, is no great comfort. The party functionaries had attacked the IPA already, and will counteract this organisation all the more from now on. The authorities reacted at once to the positive decision regarding official Soviet psychiatry. The daily Izvestiya immediately published crude disinformation about the congress results.
Who does not know how difficult it is in any case to verify how the Soviet party is meeting the set conditions? All the more difficult it will prove to convict Soviet psychiatrists, experts in lying, of the continued abuses, even under the assumption that the WPA will still wish to do so in a year. No less difficult will it prove to convene an extraordinary general assembly. Altogether impossible will it be in any voting to gather two-thirds of votes in the general assembly against official Soviet psychiatry. Who can exclude them after a year? Not those indeed who have admitted them today?

However, a particularly positive event at the congress was that the Soviet representatives were compelled publicly to admit the system of political abuse of psychiatry, although again it was not owing to the initiative of the general assembly delegates themselves. This admission is a landmark in the fight against evil - evil unveiled, but not vanquished, rather even supported today-which needs to be continued.

Paradoxical as it may be, even today a profession needs to receive treatment whose calling it is to administer treatment.

Medical abuse is a kind of AIDS that has struck 20 th century medicine. The disease-causing agent destroys the immunity system of our professionmedical ethics that protects medicine against moral decay. The phenomenon is increasingly taking on the traits of an epidemic spreading through transmission of the infection by close contact of the healthy part of medicine with the sick one, and as a consequence of neglecting prophylactic measures. The cures applied so far have not had a positive effect.

Psychiatry to this day remains the most dangerous and open focus of the said infection and psychiatrists therefore are most responsible. This responsibility is of a twofold nature - personal and collective.

Personal responsibility depends on personal participation in psychiatric repression. When this topic arises, invariably the dilemma will be: ought we to hold a psychiatrist fully responsible for a crime or should we impute part of his guilt to the state structures that compel him to a criminal medical practice? There even exists the opinion, not without foundation, that in countries with a dictatorial regime a physician cannot make his career, or even work, without infringing the laws of medical ethics.

It should, however, be remembered that a physician's dependence on the said structures is never absolute. Even in the Soviet Union, where all of medicine is 'state-run', nobody can force a physician to work in the punitive organs, say, as a psychiatrist in a special mental clinic. As a rule, doctors choose this job themselves in pursuit of personal interests, because of the advantageous working conditions. And every one of them, particularly now with all the discussion of psychiatric abuse going on, is well 
aware in advance what he will have to deal with in his future job. After finishing medical school many take on work in the Ministry of the Interior, fully of their own free will.

Not infrequently the opinion is voiced that Soviet punitive psychiatrists have been brought up by the prevailing socio-political system in the spirit of bolshevist ideology and sincerely believe that by their repressive activity they are doing their moral duty by the State. How can you accuse them when they have their own "truth", different from ours, totally different national laws, and their own view of psychological norms, outside of which any manifestation of dissidence would be placed by them? Their world outlook, so it is claimed, needs to be changed, a new legislation for psychiatry recommended and the "right" psychiatric conceptions inoculated in them.

Why then does nobody conceive of rehabilitating Mengele and his like, who too, guided by the ideology of fascism and the legislation of Hitler's Reich, considered their victims as "subhuman creatures" and did experiments on them "in the name of the national interest" and of their careers? There were even psychiatrists who welcomed the laws on sterilising and exterminating the mentally ill. Regarding the "right psychiatric conceptions"... Our American colleagues' aspiration to arm Soviet psychiatry with their own classification of mental illnesses and to contribute to the elaboration of new legislative regulations is understandable, but it will in no way influence the directions and diagnostic criteria of the punitive psychiatrists in the USSR, who when confining dissidents to a psychiatric hospital not only do not consult any classifications or legislations but often do not even set eyes on their patient. "Diagnostic criteria" indeed!

The specific character of his profession enables a physician to find a number of means to circumvent a criminal command of the authorities if he is guided by the principles of genuine humanism. Many examples are known when physicians, sometimes even at the risk of their liberty or life, have saved prisoners in Soviet labour camps from death. Such a physician, of course, will not make a career with authorities that dehumanise medicine, but neither ought he to do so by assisting these authorities in a criminal way - the medical profession's code does not allow him to. And if a physician refuses to honour this code for the sake of whatever objectives (political or personal, voluntarily or under coercion) he has essentially ceased to be a physician, becoming an antihumanist equipped with medical knowledge.

Collective responsibility falls on the psychiatrists for the indifference, tolerance, and, not infrequently, even sympathy which they manifest towards persons implicated in psychiatric abuse.

Of course criminal physicians still belong to the world of medicine. And one would wish indeed none such to be among us! Their existence throws a dark shadow over the entire profession. One would much rather sit quietly in one's consulting room, receive one's patients and not think that somewhere far away there are the likes of them, in white doctor's coats, torturing someone. Such a "flight into ignoring" in time brings about, for all of us, an ever mightier flourishing of the evil practice, not meeting any resistance. This is exemplified by cases of political abuse of psychiatry in several countries which adopted the Soviet Union's model.

But the idea of scientific cooperation with the Soviet psychiatrists is so popular! The advocates of this idea justify it in the interests of science and mutual benefit to both parties. Everybody knows the proverb, "Two heads are better than one", yet (to say nothing of the fact that every scientific achievement is used by the punitive psychiatrists) who among us would want to solve any problems, say, with a robber or murderer? Now the criminality of official Soviet psychiatry does not, it would seem, need to be proven to anyone anymore. All the more so as today the opportunity arises to cooperate with psychiatrists of the USSR on a private basis and through the Independent Psychiatric Association, which according to its statutes cannot be joined by any individual implicated in psychiatric abuse. Now regarding benefits - what benefit could outweigh the sufferings inflicted to their victims by punitive psychiatrists?

Acknowledgement of Soviet psychiatry by the other associations, as an equal partner lessens, even reduces to zero, the burden of its guilt for professional abuse and will sanction, in the last resort, a right of psychiatry to punitive functions upon a State's orders.

Now the assertion that by close cooperation it will be possible to directly influence Soviet psychiatry and that one "has to give them a chance to improve in decent society", does not hold water. The history of psychiatric abuse in the USSR is already over 20 years old. For six years the Soviet psychiatrists were outside membership in the WPA. This notwithstanding, they have from the beginning and to this day been repudiating the facts of their criminal activity. Can there be hope of "positively influencing them"?

If we by our entire behaviour increase the weight of our responsibility for the dehumanisation of our profession, we must not ask the rhetorical question: "Where do such degenerates among us come from?" We have to ask ourselves: "How could we ever permit it?" 